\title{
Storage capacity and containment issues for carbon dioxide capture and geological storage on the UK Continental Shelf
}

\author{
S. Holloway \\ British Geological Survey, Keyworth, Nottingham, NG12 5GG, UK
}

Abstract

$\mathrm{CO}_{2}$ can be stored in geological formations beneath the UK Continental Shelf as a greenhouse gas mitigation option. It can be trapped in subsurface reservoirs in structural or stratigraphic traps beneath cap rocks, as a residual $\mathrm{CO}_{2}$ saturation in pore spaces along the $\mathrm{CO}_{2}$ migration path within the reservoir rock, by dissolution into the native pore fluid (most commonly brine), by reaction of acidified groundwaters with mineral components of the reservoir rock, or by adsorption onto surfaces within the reservoir rock, e.g. onto the carbonaceous macerals that are the principal components of coal. Estimates of the $\mathrm{CO}_{2}$ storage capacity of oil and gas fields on the UKCS suggest that they could store between 1200 and $3500 \times 10^{6}$ tonnes of $\mathrm{CO}_{2}$ and up to $6100 \times 10^{6}$ tonnes $\mathrm{CO}_{2}$ respectively. Estimating the regional $\mathrm{CO}_{2}$ storage potential of saline water-bearing sedimentary rocks is resource-intensive and no UK estimates have yet taken into account all the factors that should be considered. Existing studies estimate the pore volume and likely $\mathrm{CO}_{2}$ saturation in the closed structures in a potential reservoir formation but do not take account of the potentially limiting regional pressure rise likely to occur as a result of the very large-scale $\mathrm{CO}_{2}$ injection that would be necessary to make an impact on national emissions. There is undoubtedly great storage potential in the saline water-bearing reservoir rocks of the basins around the UK, but the real challenge for studies of aquifer $\mathrm{CO}_{2}$ storage capacity in the UK is perhaps not to estimate the total theoretical $\mathrm{CO}_{2}$ storage capacity, as this is not a particularly meaningful number. Rather it is to thoroughly 
investigate selected reservoirs perceived to have good storage potential, to a standard where there is scientific consensus that the resulting storage capacity estimates are realistic. This will allow it to be considered as closer to the status of a reserve rather than a resource and will help define the scope for CCS in the UK.

\section{Keywords}

$\mathrm{CO}_{2}$ storage capacity, containment, CCS, UK

\section{Introduction}

There are many natural underground $\mathrm{CO}_{2}$ fields around the world $[\mathbf{1}, \mathbf{2}, \mathbf{3}$ ]. These are identical to natural gas fields in every respect apart from their gas composition. Furthermore many oil and natural gas fields contain varying quantities of $\mathrm{CO}_{2}$ mixed with the hydrocarbon gases [4]. Many of these fields of both pure $\mathrm{CO}_{2}$ and $\mathrm{CO}_{2-}$ hydrocarbon mixtures have existed for hundreds of thousands to tens of millions of years. This proves that under favourable circumstances large quantities of $\mathrm{CO}_{2}$ can be retained underground for appropriate timescales.

Rocks suitable for $\mathrm{CO}_{2}$ storage commonly occur in major accumulations of sedimentary rocks known as sedimentary basins that may be up to a few kilometres thick and cover thousands of square kilometres. However, although very common, sedimentary basins do not occur in every country in the world. Nor are all sedimentary basins suitable for $\mathrm{CO}_{2}$ storage; some may not contain suitable reservoir rocks, others may not contain suitable barriers to prevent injected $\mathrm{CO}_{2}$ migrating out of reservoir rocks.

\section{Typical physical conditions for geological $\mathrm{CO}_{2}$ storage}

The average temperature in many sedimentary basins increases by about $25-35^{\circ} \mathrm{C}$ $\mathrm{km}^{-1}$ below the ground surface or sea bed, as a result of heat flow from the inside to 
the outside of the Earth. However, there is considerable variation in such geothermal gradients, both locally within basins and between basins [5]. Pressure also increases downwards within the subsurface. Pressure in the pore spaces of sedimentary rocks is commonly close to hydrostatic pressure, which is the pressure generated by a column of water (or brine) of equal height to the depth of the pore space. This is because the pore space is commonly filled with water or brine and is connected, albeit tortuously, to the ground surface. There is some variation in hydrostatic pressure gradients, caused by lateral and vertical variation in the salinity of the water filling the pore space. Under conditions where the pore space is not connected to, or not in equilibrium with the surface, pressure may be greater than hydrostatic, when it is known as overpressure. The converse, underpressure, may also exist, either naturally, or as the result of abstraction of fluids such as oil and gas from a reservoir rock.

When $\mathrm{CO}_{2}$ is stored underground, there is a sharp increase in its density and corresponding decrease in volume at depths between approximately $600 \mathrm{~m}$ and 1000 m depending on the precise geothermal conditions and pressure (Figure 1). This is associated with the phase change from a gas to a dense supercritical fluid. Consequently, $\mathrm{CO}_{2}$ occupies much less space in the deep subsurface than at the surface. One tonne of $\mathrm{CO}_{2}$ at a density of $700 \mathrm{~kg} \mathrm{~m}^{-3}$ occupies $1.43 \mathrm{~m}^{3}$, but at $0^{\circ} \mathrm{C}$ and 1 atmosphere one tonne of $\mathrm{CO}_{2}$ occupies approximately $509 \mathrm{~m}^{3}$.

Under the pressure-temperature conditions commonly found in the subsurface, supercritical $\mathrm{CO}_{2}$ is less dense than, and only slightly miscible (mixes only slightly) with, the water or brine that is most commonly found within the pore spaces and fractures in sedimentary rocks. It is fully miscible (mixes completely) with, but denser than natural gas, and can be fully miscible with oil, both of which are also buoyant 
relative to water or brine. Gaseous $\mathrm{CO}_{2}$ is considerably less dense than water or oil and fully miscible with natural gas. Supercrticial $\mathrm{CO}_{2}$ has a low viscosity.

\section{Storage mechanisms}

The main mechanisms that trap $\mathrm{CO}_{2}$ in the subsurface are:

- Its buoyancy compared to water or brine, which allows it to rise through the reservoir and accumulate and be retained in structural or stratigraphic traps beneath cap rocks

- The development of a residual $\mathrm{CO}_{2}$ saturation in pore spaces along the $\mathrm{CO}_{2}$ migration path within the reservoir rock

- Dissolution into the native pore fluid (most commonly brine)

- Reaction of acidified pore waters with mineral components of the reservoir rock

- Adsorption onto surfaces within the reservoir rock, e.g. onto the carbonaceous macerals that are the principal components of coal

Geological storage of gaseous or supercritical $\mathrm{CO}_{2}$ in structural or stratigraphic traps requires a combination of a porous and permeable reservoir rock that will act as the storage reservoir and a low-permeability geological barrier such as beds of mudstone or halite in a configuration that will isolate the $\mathrm{CO}_{2}$ from the atmosphere. The efficacy of storage depends on the effectiveness of the barrier. Low-permeability barriers can be divided into two classes: aquicludes, which are rocks such as halite that are essentially impermeable if not fractured, and aquitards which are rocks such as shales and mudstones that have significant porosity but, because of their very small pore and pore throat size, have very low permeability. The porosity of aquitards is usually water-filled. If they are water-wet, i.e. water occurs as a continuous phase through the 
pore system of the rock, water (including water containing dissolved $\mathrm{CO}_{2}$ ) can pass through the porosity, albeit very slowly, in response to a pressure gradient. Water may also pass through both aquicludes and aquitards via fractures such as faults or joints, if these are present.

Most saline water-bearing reservoir rocks and oil and gas reservoirs are clastic and carbonate sedimentary rocks. Fluids flow through them via connected, commonly intergranular, porosity and/or fractures. $\mathrm{CO}_{2}$ sent for storage would be injected into them via a well or wells, at sufficient pressure to displace some of the pore fluid already present in the pore spaces and fractures. However, many reservoir formations are subdivided into compartments by faults, which may prevent, inhibit or allow the transmission of fluids. If the compartments are small and the faults are sealing, or only transmit fluids when large pressure differences develop across them, there could be a rapid pore fluid pressure rise within the compartment into which injection was taking place, and the fracture pressure of the reservoir rock or cap rock could be exceeded. Thus the $\mathrm{CO}_{2}$ storage capacity of reservoir rocks is a function not only of their intrinsic rock properties (e.g. porosity, permeability and heterogeneity) but also their size and the nature of their boundaries: a cap rock must be present above the reservoir to retain the $\mathrm{CO}_{2}$, but at least some part of the boundary of the reservoir must be able to transmit the pore fluid displaced by the injected $\mathrm{CO}_{2}$. Ultimately the displaced fluid would be accommodated by fluid movement to the seabed or water table and also perhaps, by a slight expansion of the geological system into which injection was taking place [6].

The rate of trapping by dissolution into brine will depend on how well the $\mathrm{CO}_{2}$ mixes with the formation water once it is injected into the reservoir. Once a $\mathrm{CO}_{2}$ 
accumulation has reached a stable position within the reservoir, diffusion of $\mathrm{CO}_{2}$ into the water will be faster if it is a thin but widespread accumulation, with a high surface area to volume ratio. However, for many accumulations, dissolution could be slow; in the order of thousands of years for typical injection scenarios [7], unless there is some form of active mixing induced by fluid convection within the reservoir [8]. Once $\mathrm{CO}_{2}$ has dissolved into brine, the brine becomes slightly denser than non- $\mathrm{CO}_{2}$-saturated brine and thus has negative buoyancy. Consequently the only way it can leak to the surface is if the $\mathrm{CO}_{2}$-saturated brine itself migrates closer to the surface (reducing the pressure and allowing some of the $\mathrm{CO}_{2}$ to come out of solution). There is natural fluid flow in some reservoir rocks but this is commonly in the order of centimetres per year. In hydrostatically pressured reservoirs there is no pressure gradient to drive flow.

Dissolution results in acidification of the brine into which the $\mathrm{CO}_{2}$ dissolves, which can enable chemical reactions between the acidified brine and the rock matrix or the reservoir, particularly the dissolution of carbonate minerals such as calcite and, at much slower rates, basic aluminosilicate minerals. The reaction of acidified brines with basic aluminosilicate minerals could lead to the precipitation of carbonates; socalled mineral trapping of carbon as a solid phase. However the kinetics of such reactions are very slow; time spans in the order of hundreds to thousands of years may be necessary for significant storage by this mechanism [9].

Residual saturation trapping occurs because a proportion of the injected $\mathrm{CO}_{2}$ remains behind when a plume of injected $\mathrm{CO}_{2}$ sweeps through the reservoir rock. This is trapped by capillary forces and in very small-scale structural or stratigraphic traps. Residual saturation may be in the order of 5-30\% [7] and thus it could be an important 
trapping mechanism, particularly if $\mathrm{CO}_{2}$ is injected near the base of heterogeneous reservoir formations [10].

Coal seams can be reservoirs for gases. Coal contains a natural system of orthogonal fractures known as the cleat, which imparts some permeability to it, and although the solid coal between the cleats does not contain significant conventional porosity it contains micropores in which a natural gas known as coalbed methane (CBM) can occur. This usually consists of $>90 \%$ methane plus small amounts of higher hydrocarbons and small amounts of $\mathrm{CO}_{2}$ and $\mathrm{N}_{2}$. The gas molecules are adsorbed onto the surfaces of the micropores. $\mathrm{CO}_{2}$ has a greater affinity to be adsorbed onto coal than methane. Thus, if $\mathrm{CO}_{2}$ is pumped into a coal seam, it may be stored by becoming adsorbed onto the coal, and may displace methane from the adsorption sites. Any methane recovered could have an economic value and offset some of the costs of $\mathrm{CO}_{2}$ sequestration. Experimental injection of over 100,000 tonnes $\mathrm{CO}_{2}$ into the Fruitland coal seams in the San Juan Basin, USA, has enhanced coalbed methane production [11]. However, coalbed methane production (and probably $\mathrm{CO}_{2}$ injection) can only be established in a minority of coalfields with exceptional permeability. Moreover, the methane in coal represents only a small proportion of the energy value of the coal, and the remaining energy would be sterilised if the coal were used as a $\mathrm{CO}_{2}$ storage reservoir, i.e. the coal could not be mined or gasified underground without releasing the $\mathrm{CO}_{2}$.

It might be considered advantageous to store as much of the injected $\mathrm{CO}_{2}$ as possible by the latter four mechanisms (residual saturation trapping, dissolution, geochemical reaction and adsorption) which effectively immobilise it over the very long term, as opposed to storing it as a mobile phase in structural and stratigraphic traps where 
there is a possibility that it might leak as a result of unanticipated migration pathways through the cap rock. Strategies that decrease the mobility of the injected $\mathrm{CO}_{2}$ are therefore desirable.

\section{Storage capacity}

Estimates of the availability of many geological resources such as minerals and fossil fuels are commonly divided into at least two categories: resources (accumulations of anything that is useful and potentially accessible to mankind) and reserves (that part of a resource that is available for production now, by being economically recoverable under current technological conditions).

Potential $\mathrm{CO}_{2}$ storage space in geological formations can be considered as a resource because it is potentially useful to man. However, very little of it appears to be economically exploitable now under current technological conditions and thus qualify as a reserve: incentives such as emissions trading certificates or carbon taxes are required to make geological $\mathrm{CO}_{2}$ storage cost-effective, except in some enhanced oil recovery projects.

Hence another means of subdividing the resource is required. It has been proposed $[12,13]$ that the degrees of geological and economic uncertainty associated with various parts of the resource can be considered in terms of a techno-economic resource pyramid (Figure 2).

The following categories of $\mathrm{CO}_{2}$ storage capacity, described below in ascending order, are nested within the resource-reserves pyramid:

1) Theoretical Storage Capacity is the total resource. It encompasses the whole of the resource pyramid. It assumes that the entire capacity of the system 
under consideration to store $\mathrm{CO}_{2}$ in pore space, or dissolved at maximum saturation in formation fluids, or adsorbed at $100 \%$ saturation in the entire coal mass, is accessible and utilized to its full capacity.

2) Effective Storage Capacity represents a subset of the theoretical capacity and is obtained by considering that part of the theoretical storage capacity that can be physically accessed and which meets a basic range of geological and engineering criteria. It excludes the lowest part of the pyramid.

3) Practical Storage Capacity is that subset of the effective capacity that is obtained by considering more detailed technical criteria, plus legal, regulatory, infrastructural and general economic barriers to $\mathrm{CO}_{2}$ geological storage. The Practical Storage Capacity corresponds approximately to the 'reserves' concept used in the energy and mining industries. It excludes the lowest two parts of the pyramid.

4) Matched Storage Capacity is that subset of the practical capacity that is obtained by detailed matching of large stationary $\mathrm{CO}_{2}$ sources with geological storage sites that are adequate in terms of capacity, injectivity and supply rate to contain $\mathrm{CO}_{2}$ streams sent for storage from that source or sources. This capacity includes only the top section of the resource pyramid.

At the apex of the pyramid are those storage sites or formations that have good geological characteristics, large storage capacity and are located close to emission sites with low costs of capture. At the base of the pyramid are the extremely difficult sites, with problematic geological conditions, and/or small storage capacity, which potentially may be located at great distance from sources with large capture costs and, most importantly, the resources that are speculative or poorly known. At present 
few assessments of potential storage sites in the UK have been made and the total potential storage capacity at the base of the pyramid is very much greater than that at the top, largely because much of the theoretical storage capacity is very poorly understood.

It is also recommended that all estimates of geological $\mathrm{CO}_{2}$ storage capacity should (a) clearly state the limitations that existed (data, time, knowledge) at the time the assessment was made and (b) indicate the purpose and future use to which the estimates should be applied. Assessments that lack documentation of constraints (or justification for their use) cannot be easily compared with other assessments [12].

\section{5. $\mathrm{CO}_{2}$ storage capacity in the UK}

The UK's major potential sites for the long-term geological storage of $\mathrm{CO}_{2}$ are oil and gas fields and saline water-bearing reservoir rocks. There is thought to be only limited quantifiable $\mathrm{CO}_{2}$ storage potential in coal seams in the UK for the following reasons:

- UK coal seams generally have low permeability, which is evident in the lack of success in establishing coalbed methane (CBM) production in the UK. Thirteen CBM wells had been drilled in 6 different projects to November 2004, and no commercial production had been established [14].

- Coal is an important energy mineral and its use for $\mathrm{CO}_{2}$ storage would limit the potential for mining or underground gasification of the coal in the future. Because of these potential conflicts of interest, it is not considered likely that coal resources at depths above $1500 \mathrm{~m}$ would be allocated for $\mathrm{CO}_{2}$ storage in the UK. 
There are significant coal resources in the UK at depths below $1500 \mathrm{~m}$ [14]. However, their permeability is likely to be lower even than that inferred in shallower seams because of the increased lithostatic pressures at depth. Moreover, the process by which $\mathrm{CO}_{2}$ is trapped in coal seams at temperatures above the critical point $\left(31.1^{\circ} \mathrm{C}\right)$ is not well understood. It seems that adsorption is gradually replaced by absorption and the $\mathrm{CO}_{2}$ diffuses or "dissolves" into the coal. Carbon dioxide is a "plasticizer" for coal, lowering the temperature required for its transition from a glassy brittle structure to a softer, rubbery, plastic structure. Indeed in one case, this transition temperature was interpreted to drop from about $400^{\circ} \mathrm{C}$ at $3 \mathrm{MPa}$ to $<30^{\circ} \mathrm{C}$ at $5.5 \mathrm{MPa}$. Coal plasticization or softening may adversely affect any permeability that would allow $\mathrm{CO}_{2}$ injection. Coal also swells as $\mathrm{CO}_{2}$ is adsorbed and/or absorbed, which reduces permeability by orders of magnitude or more [15]. Some studies suggest that injected $\mathrm{CO}_{2}$ may react with coal, further highlighting the difficulties in injecting $\mathrm{CO}_{2}$ into low-permeability coal [16].

\subsection{Oil and Gas fields}

Oil and gas fields are regarded as prime potential sites for $\mathrm{CO}_{2}$ storage for the following reasons:

- They have a proven seal that has retained buoyant fluids, in many cases for millions of years

- A large body of knowledge about their geological and engineering characteristics has been acquired during the exploration and production phases of development.

- In some cases there may be economic benefits to be gained from enhanced oil or gas recovery (EOR or EGR respectively) in conjunction with $\mathrm{CO}_{2}$ storage. 


\subsubsection{Oil fields}

Most of the UK's large offshore oil fields are in the Northern and Central North Sea Basin (Figure 3). However, there are three major fields (Clair, Foinaven and Schiehallion) in the Faroes-Shetland Basin, two (Douglas and Lennox) in the East Irish Sea Basin, and one (Beatrice) in the Inner Moray Firth Basin. There are also a number of onshore fields, most of which are very small. These are concentrated in the East Midlands and the Wessex Basin (in southern England). By far the largest of these is the Wytch Farm field, which underlies Poole Harbour, on the south coast of England.

It is considered probable that any $\mathrm{CO}_{2}$ storage in a $\mathrm{UK}$ oil field would take place in conjunction with enhanced oil recovery (EOR) because the potential returns from the additional oil recovered are thought likely to exceed the extra costs involved.

However, the costs of adapting offshore platforms and other infrastructure for EOR as opposed to pure $\mathrm{CO}_{2}$ storage are not well known at present. Moreover, the economics of EOR offshore are dependent on the oil price and potentially on the price of $\mathrm{CO}_{2}$ in the EU ETS, both of which have shown volatility over the last few years.

\section{Storage Capacity of the UK's Onshore Oil Fields}

With one exception, the UK's onshore oil fields are too small to have any significant $\mathrm{CO}_{2}$ storage capacity. The exception is the Wytch Farm oil field, Dorset, which is significantly larger than any of the other onshore fields, is partially offshore and is considered in the estimate for offshore fields given below.

\section{Storage Capacity of the UK's Offshore Oil Fields}

The most detailed estimate of the $\mathrm{CO}_{2}$ storage capacity of the UK's offshore oil fields in the public domain is an estimate of the mass of $\mathrm{CO}_{2}$ likely to be retained in the 
fields as a result of stand-alone EOR [17], currently downloadable at http://www.ogmrp.com/dissemination/co2/co2_ogmrp_overview_update_eb250406.pdf (accessed 29/4/2008). It is based on field-by-field $\mathrm{CO}_{2}$-EOR retention estimates, made for the DTI (now DBERR) between 1989 and 1991. The study included an initial screening in which fields were excluded from consideration if they had already ceased production, their predicted close of production dates were too close, the stock tank oil initially in place was less than 100 million barrels, they were field types where the outcome of EOR was uncertain, viz. viscous oil fields, thin oil rims, fractured reservoirs, gas/condensate fields, or they were not considered suitable candidates for EOR for other technical reasons. The results of this study were updated in 2006, and include graphs showing the window of opportunity for $\mathrm{CO}_{2}$ storage and potential annual $\mathrm{CO}_{2}$ storage rates resulting from EOR.

The total $\mathrm{CO}_{2}$ storage capacity of the oil fields is estimated to be approximately 1200 million tonnes. There may be upside potential because this figure does not include any $\mathrm{CO}_{2}$ storage that might take place after stand-alone EOR had ceased. On the other hand it may be optimistic because it assumes that EOR will be deployed at all the technically suitable large oil fields.

Currently, the data indicate that the window of opportunity for EOR stretches out to 2030, and 2011 is a key year for implementing $\mathrm{CO}_{2}$ storage associated with EOR in the UK's oil fields as the available storage capacity drops markedly thereafter. However, latest start dates for EOR in each field are influenced by close of production dates which themselves are influenced by economic factors including the price of oil, which has risen greatly during the last few years. 
The level of technical detail that has gone into these estimates is high, and potential annual $\mathrm{CO}_{2}$ storage rates have been calculated, although field-by-field estimates are not in the public domain. Therefore they can probably be considered "matched capacity” in terms of [13].

It is possible that economic EOR could either continue for longer and thus store more $\mathrm{CO}_{2}$, or be optimised to store more $\mathrm{CO}_{2}$, if a value could be assigned to $\mathrm{CO}_{2}$ storage via a mechanism such as the EU Emissions Trading Scheme (EU ETS). For example, it has been estimated that the maximum $\mathrm{CO}_{2}$ storage capacity of the oil fields in the UK sector is $1.8 \mathrm{Gt} \mathrm{CO}_{2}$ when standard EOR practices are applied [18]. Standard EOR practices imply the minimization of $\mathrm{CO}_{2}$ usage and the maximization of $\mathrm{CO}_{2}$ recovery after injection underground, to reduce the costs of the process by reducing $\mathrm{CO}_{2}$ purchases. If the storage of $\mathrm{CO}_{2}$ had a commercial value, for example through emissions trading, $\mathrm{CO}_{2}$-EOR operations could be designed to maximize the retention of $\mathrm{CO}_{2}$ underground. In this case, it is suggested the UK storage capacity could increase to approximately 3.5 Gt [18].

Thus the potential $\mathrm{CO}_{2}$ storage capacity of the UK's oil fields depends on assumptions about how they will be exploited. The potential ranges from approximately $1200 \mathrm{Gt} \mathrm{CO}_{2}$ to approximately $3.5 \mathrm{Gt} \mathrm{CO}_{2}$. It is considered that the most rigorous estimates are those made for the DTI [17] and therefore the realistic potential is much closer to the former figure than the latter.

How much oil could be recovered by EOR in the UK oil fields?

It has been estimated that approximately 2 billion additional barrels of oil could be recovered by economic EOR on the UKCS [17]. Disregarding economics, approximately 2.7 billion barrels (range between 1.8 and 3.7 billion barrels depending 
on the achievable oil recovery from each oil field), or 58\% of the UK proven reserves in 2003, could be recovered from the UK sector of the North Sea [18].

$\mathrm{CO}_{2}$-enhanced oil recovery in North American onshore oilfields regularly recovers 4$12 \%$ of the oil initially in place [19]. A study of a section of the Forties oil field (UK North Sea) indicated that WAG $\mathrm{CO}_{2}$-EOR could recover up to an additional $9.8 \%$ of the oil initially in place [20].

\subsubsection{Storage Capacity of the UK's Gas Fields}

\section{Onshore Gas Fields}

The UK's onshore gas fields are all too small to have significant $\mathrm{CO}_{2}$ storage capacity. They are also in high demand as natural gas storage sites. The largest onshore field is Saltfleetby, in Lincolnshire. This has ultimately recoverable reserves of $2.067 \times 10^{9}$ standard $\mathrm{m}^{3}$ natural gas and is estimated to have a $\mathrm{CO}_{2}$ storage capacity of $5 \mathrm{Mt} \mathrm{CO}_{2}$ or less. Moreover, some of the infrastructure that has been installed has been laid out in anticipation of future use as a natural gas storage site [21], implying that it will not be available for $\mathrm{CO}_{2}$ storage in the foreseeable future.

\section{Offshore Gas Fields}

The term gas field is applied here to hydrocarbon fields sometimes known as 'dry' gas fields because they contain methane plus only low amounts of the higher hydrocarbons that may be gaseous at reservoir conditions but which condense at surface temperatures and pressures. In other words they do not generate liquid condensate at surface conditions. Fields that contain relatively high amounts of higher hydrocarbons that are gaseous at reservoir conditions but which condense at surface temperatures and pressures are described as wet gas fields. Gas condensate fields are fields in which the hydrocarbons are gaseous at initial reservoir conditions, but they 
contain very significant proportion of higher hydrocarbons which can condense to liquids in the reservoir if the pressure drops below its dew-point. They also produce condensates at the surface.

The UK’s offshore gas fields occur mainly in two areas: the Southern North Sea Basin and the East Irish Sea Basin (Figure 3). However, there is also one major depleted gas field (Frigg) in the Northern and Central North Sea Basin. The gas condensate fields are all in the Central and Northern North Sea Basin.

\section{The Southern North Sea fields}

The majority of the gas field reservoirs in the UK sector of the Southern North Sea are in the Leman Sandstone Formation, a sandstone reservoir rock of Permian age. However, there are several fields with Carboniferous sandstone reservoirs and a few with reservoirs in the Bunter Sandstone Formation, which is of Triassic age. There are also some small discoveries with reservoirs in Upper Permian (Zechstein) carbonates.

Some of the Rotliegend gas reservoirs are highly compartmentalised, i.e. they are divided into compartments by faults that act as permeability barriers. This is significant because each compartment in which $\mathrm{CO}_{2}$ is stored is likely to require a separate $\mathrm{CO}_{2}$ injection well, adding to the cost of storage. By contrast, the Triassic reservoirs do not appear to be significantly compartmentalised.

The majority of the fields with Rotliegend (Leman Sandstone) reservoirs are depletion-drive fields, i.e. there is little water encroachment into the field from surrounding parts of the reservoir rock during production. This means that there will be significant volumes of pore space in the field filled with low-pressure natural gas at the time that production ceases. This is advantageous for $\mathrm{CO}_{2}$ injection because the various reservoir compartments can be filled with $\mathrm{CO}_{2}$ and the initial reservoir 
pressure may never have to be exceeded, significantly lowering the risk of leakage. At least some of the Carboniferous and Triassic fields have significant water drive, i.e. water does encroach into the field from surrounding parts of the reservoir rock during production. One exception is the Triassic Hewett Sandstone reservoir in the Hewett field.

\section{The East Irish Sea fields}

The East Irish Sea Basin fields all have reservoirs in the Ormskirk Sandstone Formation, which is of Triassic age and forms the uppermost part of the Sherwood Sandstone Group. They are sealed by the overlying Mercia Mudstone Group, which contains thick units of halite (rock salt). The two largest fields, South Morecambe and North Morecambe are principally depletion drive fields.

\section{Northern and Central North Sea Fields}

The now depleted Frigg field was the largest of the dry gas fields in the Northern and Central North Sea Basin, and the only significantly sized field outside the Southern North Sea and East Irish Sea Basins. It straddles the UK/Norway median line (Figure 3). It had strong water drive.

\section{Storage capacity estimates}

Based on the assumption that all fields would be filled with $\mathrm{CO}_{2}$ to their initial (preproduction) pressure, total storage capacity in the gas fields in the UK sector of the Southern North Sea is estimated to be approximately 3.9 Gt $\mathrm{CO}_{2}$ [22] and total storage capacity in the East Irish Sea Basin is estimated at approximately $1 \mathrm{Gt} \mathrm{CO}_{2}$ [23].

It has been estimated that up to 4.6\% EGR might be achievable in typical Leman Sandstone Southern North Sea gas fields, with low reservoir pressures and low $\mathrm{CO}_{2}$ 
injection rates. However, this would require investment in an additional injection well in each compartment of the field [24].

\subsubsection{Gas Condensate Fields}

Gas condensate fields contain principally methane, butane, pentanes and higher hydrocarbons. This hydrocarbon mixture is in the gaseous phase in the reservoir, but the pentanes and higher hydrocarbons condense to liquids at surface temperature and pressure. In the UK, gas condensate fields are only found in the Northern and Central North Sea Basin (Figure 3). Less field-by-field public domain information on their drive mechanism is available, but a crude estimate of their $\mathrm{CO}_{2}$ storage capacity, using the same assumptions that were made for the dry gas fields, is $1.2 \mathrm{Gt}^{\mathrm{CO}_{2}}$ [22].

\subsubsection{Saline water-bearing reservoir rocks (saline aquifers)}

The $\mathrm{CO}_{2}$ storage capacity of saline water-bearing reservoir rocks is extremely difficult to estimate, particularly on a regional basis. The storage capacity of a small volume of an aquifer such as an individual structural closure can be estimated by numerical simulation of $\mathrm{CO}_{2}$ injection. At least three of the five potential $\mathrm{CO}_{2}$ trapping mechanisms should be taken into account (geochemical trapping can often be neglected on the grounds that it is such a slow process that it is unlikely to affect storage capacity over injection timescales and adsorption is not likely to be significant unless the reservoir contains significant volumes of coal). Detailed knowledge of the reservoir properties, the structure of the reservoir and the structure and hydraulic properties of surrounding strata are required for accurate simulation.

The limits to the amounts of $\mathrm{CO}_{2}$ that could be stored in any part of, or an entire, aquifer are determined by the thresholds at which adverse effects will occur. The most important of these is commonly leakage from the storage reservoir but the potential to 
adversely affect other legitimate uses of the subsurface, ground surface or marine environment may also need to be considered.

It is commonly uncertain whether, or under what conditions, structural or stratigraphic traps in aquifers are gas-tight, i.e. will not leak when filled with $\mathrm{CO}_{2}$. The principal means by which $\mathrm{CO}_{2}$ is likely to leak through the natural sealing system is through capillary entry into the sealing formation or through fractures in the sealing formation, which may be on various scales. The potential for capillary leakage through the seal can be estimated from laboratory capillary entry pressure measurements. Geomechanical tests or modelling can be used to estimate the limiting reservoir pressure above which any faults or fractures might slip or dilate, or fractures might be induced in the reservoir rock or sealing formations: the maximum safe local or regional pore fluid pressure rise induced by $\mathrm{CO}_{2}$ injection can potentially be a significant constraint on storage capacity. Inducing regional pore fluid pressure rise in a reservoir formation could be construed as interfering with other $\mathrm{CO}_{2}$ storage operations, or even oil or gas production. The integrity of any wells on the migration path of the injected $\mathrm{CO}_{2}$ also needs to be considered, as does the impact of acidified pore water (caused by $\mathrm{CO}_{2}$ dissolution into the native pore water found in the aquifer) on the entire system - including any wells.

There are also cultural constraints that restrict the $\mathrm{CO}_{2}$ storage potential in aquifers, particularly in onshore and nearshore regions. Those parts of aquifers that contain potable water should be protected from potential contamination by injected $\mathrm{CO}_{2}$ or displaced saline water or entrained substances such as oil or heavy metals mobilised by $\mathrm{CO}_{2}$ injection.

$\mathrm{CO}_{2}$ storage potential in UK onshore saline water-bearing reservoir rocks 
Amongst the major deep aquifers of onshore Britain, there is, in general, a correspondence between sandstones that have sufficient porosity and permeability to form a low-enthalpy geothermal resource [25] and those that have the potential for $\mathrm{CO}_{2}$ storage. These sandstones also tend to be used for water supply in areas where they crop out at the surface or are buried to only shallow depths and consequently are unlikely to be considered for $\mathrm{CO}_{2}$ storage. Only the Lower Greensand, Portland Sand, Sherwood Sandstone and various Permian sandstones are considered sufficiently porous and permeable to have large-scale $\mathrm{CO}_{2}$ storage potential [26].

\section{$\mathrm{CO}_{2}$ storage potential in UK offshore saline water-bearing reservoir rocks}

Attempts have been made to estimate the theoretical $\mathrm{CO}_{2}$ storage capacity of various areas or formations within the UKCS [22, 23, 27]. These indicate several ${\mathrm{Gt} \mathrm{CO}_{2}}$ storage capacity in the Southern North Sea Basin and some more limited potential (up to $0.63 \mathrm{Gt}$ ) in the East Irish Sea Basin. However, none of these studies take into account all the major factors that should be considered in such an analysis and so the saline aquifer $\mathrm{CO}_{2}$ storage capacity even of these regions needs to be revisited. In particular, the local and regional pore fluid pressure rise in a potential saline aquifer storage formation needs to be considered as well as the pore volume and the $\mathrm{CO}_{2}$ saturation that is likely to be achieved in the closed structures. This requires numerical simulation of concurrent multiple $\mathrm{CO}_{2}$ injection projects in the aquifer as a whole.

Such simulation needs to take into account the hydraulic properties of the surrounding strata as well as the potential storage reservoir.

\section{Conclusions}

There is very significant $\mathrm{CO}_{2}$ storage capacity in the UK's oil and gas fields.

Accessing and utilising this is a significant issue under present economic conditions. There is undoubtedly great storage potential in the saline water-bearing reservoir 
rocks of the basins around the UK as well, but calculating the magnitude of this potential resource is beset with problems. The real challenge for studies of aquifer $\mathrm{CO}_{2}$ storage capacity in the $\mathrm{UK}$ is perhaps not to estimate the total theoretical $\mathrm{CO}_{2}$ storage capacity, as this is not a particularly meaningful number. Rather it is to thoroughly investigate selected reservoirs perceived to have good storage potential, to a standard where there is scientific consensus that the resulting storage capacity estimates are realistic. This will allow it to be considered as closer to the status of a reserve rather than a resource and will help define the scope for CCS in the UK.

\section{Acknowledgements}

This paper is published with the permission of the Director of the British Geological Survey (NERC). The author would like to thank the UK Department of Energy and Climate Change Cleaner Fossil Fuels Programme, which funded work on which parts of the paper are based.

\section{References}

1 Studlick, J.R.J., Shew, R.D., Basye, G.L. and Ray, J.R. 1990. A giant carbon dioxide accumulation in the Norphlet Formation, Pisgah Anticline, Mississippi. In Sandstone Petroleum Reservoirs (ed. J. Barwis, J.G. McPherson \& J.R.J. Studlick), pp.181-203. New York: Springer-Verlag.

2 Pearce, J.M., Holloway, S., Wacker, H., Nelis, M.K., Rochelle, C.A. and Bateman, K. 1996. Natural occurrences as analogues for carbon dioxide disposal. Energy Conversion and Management 37 (6-8), 1123-1128.

3 Stevens, S.H. 2005. Natural $\mathrm{CO}_{2}$ Fields as Analogs for Geologic $\mathrm{CO}_{2}$ Storage. In Carbon Dioxide Capture For Storage in Deep Geologic Formations Results from the $\mathrm{CO}_{2}$ Capture Project (ed. D.C. Thomas \& S.M. Benson), Vol. 2, Geologic Storage of Carbon Dioxide with Monitoring and Verification pp. 687-697. Oxford: Elsevier. 
4 Baines, S.J. and Worden, R.H. 2004. The long-term fate of $\mathrm{CO}_{2}$ in the subsurface: natural analogues for $\mathrm{CO}_{2}$ storage. In Geological Storage of Carbon Dioxide (ed. S.J. Baines \& R.H. Worden), Geological Society, London, Special Publications 233, 59-85.

5 Tissot, B.P. and Welte, D.H. 1978. Petroleum Formation and Occurrence: A New Approach to Oil and Gas Exploration. Berlin, Springer-Verlag.

6 Van der Meer, L.G.H. 1992. Investigation regarding the storage of carbon dioxide in aquifers in the Netherlands. Energy Conversion and Management, 33 (5-8), 611-618.

7 Ennis-King, J and Paterson, L. 2001. Reservoir Engineering Issues in the Geological Disposal of Carbon Dioxide, p.290-295 in: Proceedings of the $5^{\text {th }}$ International Conference on Greenhouse Gas Control Technologies, Williams D, Durie B, McMullan P, Paulson C \& Smith A (editors), Collingwood, Australia: CSIRO.

8 Lindeberg, E. and Wessel-Berg, D. 1997. Vertical convection in an aquifer column under a gas cap of $\mathrm{CO}_{2}$. Energy Conversion and Management 38 (Supplement), S229-S234.

9 Xu, T., Apps, J.A. and Pruess, K. 2003. Reactive geochemical transport simulation to study mineral trapping for $\mathrm{CO}_{2}$ disposal in deep arenaceous formations. Journal of Geophysical Research, 108(B2), 2071-2084.

10 Flett, M.A., Gurton, R.M. and Taggart, I.J. 2005. Heterogeneous Saline Formations: Long-term Benefits for Geo-sequestration of Greenhouse Gases. In: E.S. Rubin, D.W. Keith and C.F. Gilboy (eds.), Proceedings of 7th International Conference on Greenhouse Gas Control Technologies. Volume 
1: Peer-Reviewed Papers and Overviews, Oxford, United Kingdom: Elsevier, 501-509.

11 Reeves, S.R. 2005. The Coal-Seq Project: Key Results from Field, Laboratory and Modeling Studies. In Proceedings of 7th International Conference on Greenhouse Gas Control Technologies (ed. E.S. Rubin, D.W. Keith \& C.F. Gilboy), Vol. 2 Contributed Papers and Panel Discussion, pp. 1399-1403. Oxford: Elsevier.

12 Bradshaw. J., Bachu, S., Bonijoly, D., Burruss, R., Holloway, S., Christensen N-P. and Mathiasen, O-M. 2007. $\mathrm{CO}_{2}$ storage capacity estimation: Issues and development of standards. International Journal of Greenhouse Gas Control, 1, 62-68.

13 Bachu, S., Bonijoly, D., Bradshaw, J., Burruss, R., Holloway, S., Christensen, N-P. and Mathiassen, O-M. 2007. $\mathrm{CO}_{2}$ storage capacity estimation: Methodology and gaps. International Journal of Greenhouse Gas Control, 1, 430-443.

14 Jones, N.S., Holloway, S., Smith, N.J.P., Browne, M.A.E., Creedy, D.P., Garner, K. and Durucan, S. 2004. UK Coal Resource for New Exploitation Technologies. DTI Report No. COAL R271, DTI/Pub URN 04/1879. DTI Cleaner Coal Technology Transfer Programme, Harwell.

15 Shi, J-Q. and Durucan, S. 2005. A numerical simulation study of the Allison Unit $\mathrm{CO}_{2}$-ECBM pilot: the effect of matrix shrinkage and swelling on ECBM production and $\mathrm{CO}_{2}$ injectivity. In: E.S. Rubin, D.W. Keith and C.F. Gilboy (eds.), Proceedings of 7th International Conference on Greenhouse Gas Control Technologies. Volume 1: Peer-Reviewed Papers and Overviews, Oxford, United Kingdom: Elsevier, 431-442. 
on Carbon Dioxide Capture and Storage. B. Metz, O. Davidson, L. Meyer and H.C. de Coninck (eds.), Cambridge University Press, Cambridge, United Kingdom, and New York, USA.

17 Anon. 2006. $\mathrm{CO}_{2}$-flooding of UKCS Reservoirs. http://www.ogmrp.com/dissemination/co2/co2_ogmrp_overview_update_eb250406.pdf

18 Tzimas, E., Georgakaki, A., Garcia Cortes, C. and Peteves, S.D. 2005. Enhanced Oil Recovery using Carbon Dioxide in the European Energy System. European Commission Directorate General Joint Research Centre Report EUR 21895 EN, Institute for Energy, Petten, Netherlands. http://www.jrc.nl/

19 Balbinski, E. 2002. Potential UKCS $\mathrm{CO}_{2}$ Retention Capacity from IOR Projects. http://ior.senergyltd.com/issue3/co2/ecl_retention/page1.htm

20 Cawley, S. Saunders, M.R., Le Gallo, Y., Carpentier, B., Holloway, S., Kirby, G.A., Bennison, T., Wickens, L., Wickramaratna, R, Bidstrup, T., Arkley, S.L.B., Browne, M.A.E. and J.M. Ketzer. 2005. The NGCAS project - Assessing the potential for EOR and $\mathrm{CO}_{2}$ storage at the Forties Oilfield, Offshore UK. In: S.M. Benson (ed.) Carbon Dioxide Capture For Storage in Deep Geologic Formations - Results from the $\mathrm{CO}_{2}$ Capture Project, Volume 2: Geologic Storage of Carbon Dioxide with Monitoring and Verification. Elsevier, Oxford, United Kingdom, p. 713-750.

21 Hodge, T. 2003. The Saltfleetby Field, Block L 47/16, Licence PEDL 005, Onshore UK. In: Gluyas, J.G. and H.M. Hichens (eds), 2003, United Kingdom Oil and Gas Fields, Commemorative Millenium Volume, Geological Society, London, Memoirs, 20, 911-919. 
22 DTI 2006. The Valleys energy project, a case study. Project Summary 340, Carbon Abatement Technologies Programme, Building 329, Harwell International Business Centre, Didcot, Oxfordshire, OX11 0QJ. Available for download at: http://www.dti.gov.uk/files/file30690.pdf?pubpdfdload=06\%2F884.

23 Kirk, K.L. 2006. Storing carbon dioxide in the rocks beneath the East Irish Sea. Proceedings of the GHGT-8 Conference, Trondheim, Norway, 19-22 June 2006. ISBN: 0-08-046407-6, Elsevier, published on CD.

24 Paterson, G. 2003. Enhanced Gas Recovery Potential from $\mathrm{CO}_{2}$ Injection into Depleted Dry Gas Reservoirs. Sharp IOR eNewsletter, October 2003, Issue 6. http://ior.senergyltd.com/issue6/rnd/SMEs/ECL_CO2/ecl_co2.htm, accessed May 2008.

25 Downing, R.A. and Gray, D. (eds.) 1986. Geothermal Energy - The Potential in the United Kingdom. HMSO for British Geological Survey, London, 187 pp.

26 Holloway, S. and Baily, H.E. 1996 . The $\mathrm{CO}_{2}$ Storage Capacity of the United Kingdom. In: In: Holloway, S. (ed.), The Underground Disposal of Carbon Dioxide. Final Report of Joule 2 Project No. CT92-0031. British Geological Survey, Keyworth, Nottingham, pp. 92-105

27 Holloway, S., Vincent, C.J., Bentham, M.S. and K. L. Kirk., K.L. 2006. Top-down and bottom-up estimates of $\mathrm{CO}_{2}$ storage capacity in the UK sector of the Southern North Sea Basin. Environmental Geoscience, 13(2): 74-81. 


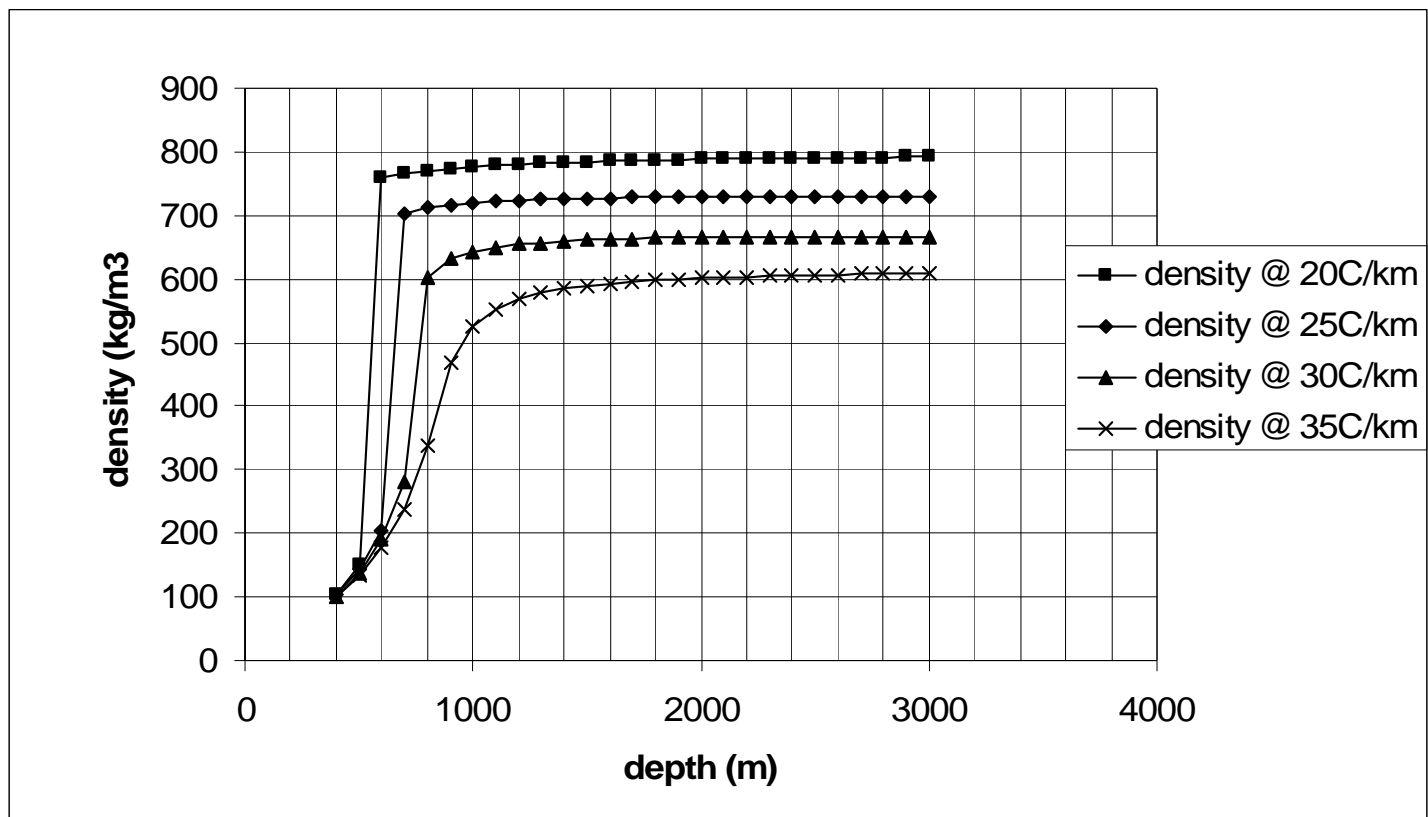

Figure 1. Density of $\mathrm{CO}_{2}$ at a range of geothermal gradients typically found in sedimentary basins, assuming a surface temperature of $10^{\circ} \mathrm{C}$ and a hydrostatic pressure gradient. 


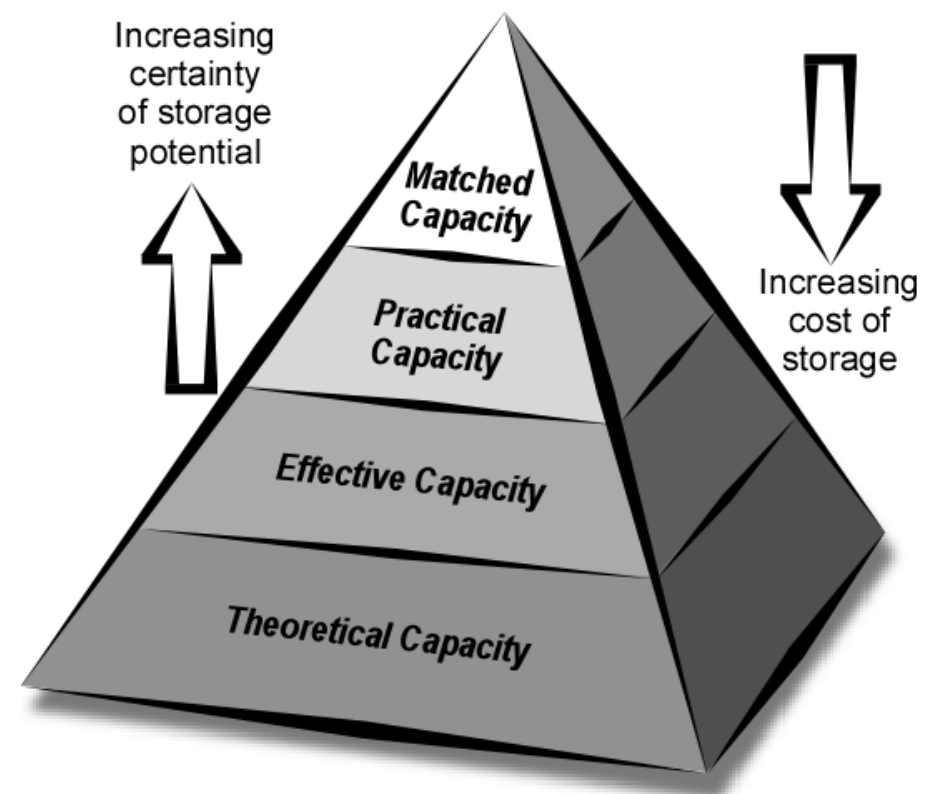

Figure 2. Techno-Economic Resource-Reserve pyramid for $\mathrm{CO}_{2}$ storage capacity in geological media within a jurisdiction or geographic region. The pyramid shows the relationship between Theoretical, Effective, Practical and Matched capacities (from Bachu et al. 2007). 


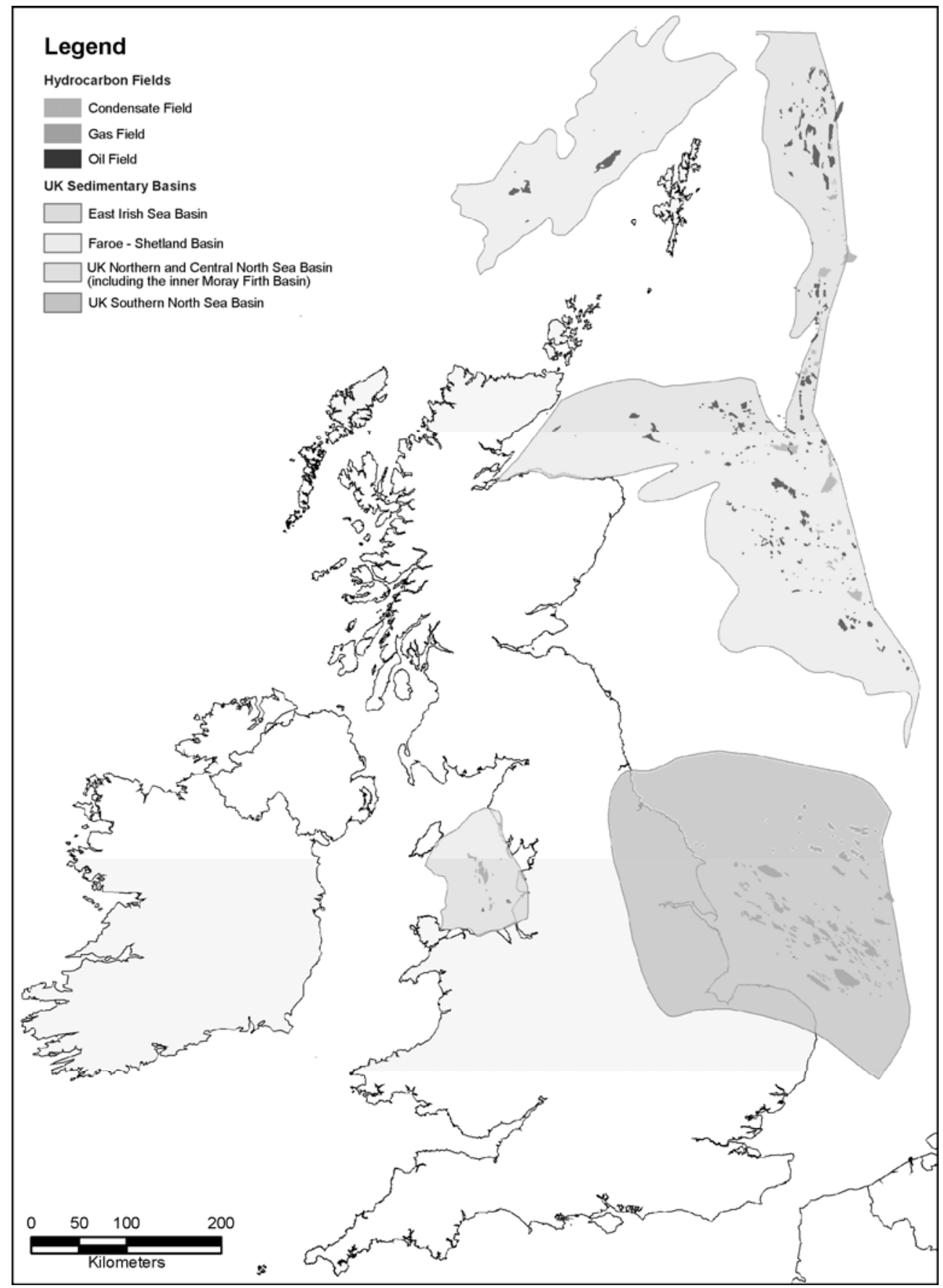

Figure 3. Map showing the location of offshore hydrocarbon fields and the major oil and gas-bearing sedimentary basins in the UK Continental Shelf. 